\title{
iTRAQ-Based Quantitative Proteomic Analysis Identified HSC71 as a Novel Serum Biomarker for Renal Cell Carcinoma
}

\author{
Yushi Zhang, Yi Cai, Hongyan Yu, and Hanzhong Li \\ Department of Urology, Peking Union Medical College Hospital, Chinese Academy of Medical Sciences and \\ Peking Union Medical College, Beijing 100730, China \\ Correspondence should be addressed to Hanzhong Li; lihanzhongdoc@126.com
}

Received 27 October 2014; Revised 14 February 2015; Accepted 2 March 2015

Academic Editor: Haifeng Yang

Copyright (C) 2015 Yushi Zhang et al. This is an open access article distributed under the Creative Commons Attribution License, which permits unrestricted use, distribution, and reproduction in any medium, provided the original work is properly cited.

\begin{abstract}
Renal cell carcinoma (RCC) is one of the most lethal urologic cancers and about $80 \%$ of RCC are of the clear-cell type (ccRCC). However, there are no serum biomarkers for the accurate diagnosis of RCC. In this study, we performed a quantitative proteomic analysis on serum samples from ccRCC patients and control group by using isobaric tag for relative and absolute quantitation (iTRAQ) labeling and LC-MS/MS analysis to access differentially expressed proteins. Overall, 16 proteins were significantly upregulated (ratio $>1.5$ ) and 14 proteins were significantly downregulated (ratio $<0.67$ ) in early-stage ccRCC compared to control group. HSC71 was selected and subsequently validated by Western blot in six independent sets of patients. ELISA subsequently confirmed HSC71 as a potential serum biomarker for distinguishing RCC from benign urologic disease with an operating characteristic curve (ROC) area under the curve (AUC) of 0.86 ( $95 \%$ confidence interval (CI), 0.76 0.96), achieving sensitivity of $87 \%$ (95\% CI 69\% 96\%) at a specificity of $80 \%$ (95\% CI 61 92\%) with a threshold of $15 \mathrm{ng} / \mathrm{mL}$. iTRAQ-based quantitative proteomic analysis led to identification of serum HSC71 as a novel serum biomarker of RCC, particularly useful in early diagnosis of ccRCC.
\end{abstract}

\section{Introduction}

Renal cell carcinoma (RCC) is the most frequent form of kidney cancer, with an increasing incidence over the past decades [1]. The majority of RCC are of the clearcell type (ccRCC), which accounts for approximately $80 \%$ of kidney cancer [2]. Early diagnosis of RCC is one of the most important factors contributing to the successful treatment and favorable prognosis. The diagnosis of RCC is mainly based on imaging findings, which however has limited accuracy and cannot be used reliably to confirm the nature of the lesion [3]. Due to the increase of disease rates, together with the fact that there are no serum biomarkers available, inexpensive and noninvasive test of prediction for RCC would be urgently required for the early detection of RCC. Serum and plasma, containing proteins both secreted and shed from tumor cells, are ideal fluids for the detection of cancer biomarkers since they are characterized by ease of sampling and storing. However, their variable composition and vast dynamic range of proteins present in serum pose tremendous technical challenges in identifying clinically relevant biomarkers [4]. A recently novel proteomics named isobaric tags for relative and absolute quantification (iTRAQ) combined with mass spectrometry technology (LC-MS/MS) now represents a powerful tool for identification of cancer biomarkers [5]. The iTRAQ technology has been successfully applied to biomarker screening of multiple tumors and diseases in both tissue and serum samples [6].

In this study, we performed quantitative proteomic analysis using the iTRAQ and LC-MS/MS to identify proteins dysregulated in serum of early-stage ccRCC patients compared to healthy people. We revealed differential expression of a number of proteins in serum of ccRCC patients compared with control group. In addition, we confirmed the most dysregulated expression of heat shock cognate $71 \mathrm{kDa}$ protein (HSC71) on six independent sets of serum by Western blot. ELISA subsequently confirmed HSC71 as a potential serum biomarker for diagnosis of RCC. 
TABLE 1: Description and comparison of clinical and laboratory characteristics of the study subjects.

\begin{tabular}{|c|c|c|c|c|}
\hline \multirow{2}{*}{ Characteristic } & \multicolumn{2}{|c|}{ Discovery samples by iTRAQ } & \multicolumn{2}{|c|}{ Validation samples by ELISA } \\
\hline & $\operatorname{RCC}(n=10)$ & Control $(n=10)$ & $\operatorname{RCC}(n=30)$ & Control $(n=30)$ \\
\hline Age (years) & $54.80 \pm 13.32$ & $52.80 \pm 9.13$ & $53.10 \pm 13.33$ & $55.63 \pm 13.98$ \\
\hline Gender (male/female) & $7 / 3$ & $7 / 3$ & $18 / 12$ & $16 / 14$ \\
\hline BMI & $22.86 \pm 2.57$ & $22.55 \pm 2.55$ & $21.78 \pm 2.83$ & $22.16 \pm 3.02$ \\
\hline Hypertension & $4(40 \%)$ & $2(20 \%)$ & $6(20 \%)$ & $4(13.3 \%)$ \\
\hline Diabetes mellitus & $2(20 \%)$ & $1(10 \%)$ & $5(16.7 \%)$ & $3(10 \%)$ \\
\hline Smoking & $3(30 \%)$ & $3(30 \%)$ & $7(23.3 \%)$ & $6(20 \%)$ \\
\hline \multicolumn{5}{|l|}{ Pathological stage } \\
\hline pT1 & $10(100 \%)$ & & $16(53.3 \%)$ & \\
\hline pT2 & & & $11(36.7 \%)$ & \\
\hline pT3 & & & $2(6.7 \%)$ & \\
\hline pT4 & & & $1(3.3 \%)$ & \\
\hline M0 & $10(100 \%)$ & & $28(93.3 \%)$ & \\
\hline M1 & & & $2(6.7 \%)$ & \\
\hline \multicolumn{5}{|l|}{ Fuhrman grades } \\
\hline G1-2 & $10(100 \%)$ & & $21(70 \%)$ & \\
\hline G3-4 & & & $9(30 \%)$ & \\
\hline \multicolumn{5}{|l|}{ Histological subtype } \\
\hline Clear-cell & $10(100 \%)$ & & $23(76.7 \%)$ & \\
\hline Papillary & & & $3(10 \%)$ & \\
\hline Chromophobe & & & $4(13.3 \%)$ & \\
\hline
\end{tabular}

Data are expressed as $n(\%)$, or mean \pm SD. RCC: renal cell carcinoma.

\section{Materials and Methods}

2.1. Patients and Serum Collection. This study was approved by the Human Ethics Committee of Peking Union Medical College Hospital. Serum samples from healthy volunteers and patients were all collected from the Department of Urology at Peking Union Medical College Hospital between October 2013 and October 2014. The control group consisted of 10 healthy controls and 20 patients diagnosed with other urologic diseases such as angiomyolipoma of kidney (10 patients), benign prostatic hyperplasia (4 patients), urinary tract infection (4 patients), and urolithiasis ( 2 patients). The detailed demographic profiles of the participants are provided in Table 1. All samples were collected before breakfast, then centrifuged at $3000 \mathrm{~g}$ for $15 \mathrm{~min}$ at $4^{\circ} \mathrm{C}$, and subsequently stored at $-80^{\circ} \mathrm{C}$ prior to further processing. All serum samples were collected before any treatment or surgery.

2.2. Affinity Depletion of Serum Samples. To reduce the individual differences, sera collected were pooled into two groups, each containing sera from 10 RCC patients or 10 healthy people. Pooled serum samples were depleted of the 14 high-abundance proteins using a high capacity $4.6 \times 100 \mathrm{~mm}$ multiple affinity removal column (Agilent Technologies, CA). Approximately $35 \mu \mathrm{L}$ of serum was processed per sample and analyzed with the Agilent 1260 HPLC system according to the manufacturer's protocol. Protein concentrations were determined using a Bradford protein assay kit (Pierce). All measurements were performed in duplicate.

2.3. iTRAQ Labeling and Strong Cation Exchange Liquid Chromatography. Prior to iTRAQ labeling, the samples were concentrated and desalted using $10 \mathrm{kDa}$ molecular weight cutoff spin concentrators (Millipore). Then, $100 \mu \mathrm{g}$ peptides from each sample were labeled with the iTRAQ reagents according to the manufacturer's instructions and as previously described [7]. Peptides were labeled individually with iTRAQ tag (Applied Biosystems, USA) as follows: 114.1 for ccRCC and 115.1 for control group, respectively. To reduce sample complexity, labeled samples were pooled and fractionated by strong cation exchange (SCX) using a Polysulfoethyl A column (PolyLC Inc., USA) as previously described [7].

2.4. Reverse-Phase LC-MS/MS Analysis. Dried SCX fractions were reconstituted in $100 \mathrm{~mL}$ of buffer A (5\% acetonitrile; $95 \% \mathrm{H}_{2} \mathrm{O} ; 0.1 \%$ formic acid) and loaded into a reversephase C18 Peptide Captrap (Agilent Technologies, USA). After desalting, peptides were eluted by running a $5 \%$ to $80 \%$ buffer $\mathrm{B}$ gradient (95\% acetonitrile; $5 \% \mathrm{H}_{2} \mathrm{O} ; 0.1 \%$ formic acid) at a flow rate of $0.4 \mu \mathrm{L} / \mathrm{min}$ for $65 \mathrm{~min}$. The $\mathrm{LC}$ elution was subjected to positive-ion nanoflow electrospray analysis using a Qstar XL MS/MS system (Applied Biosystems Inc., USA). A survey scan was acquired from $\mathrm{m} / \mathrm{z} 400-1800$ for 
$0.5 \mathrm{~s}$ with up to four precursor ions selected from $\mathrm{m} / z 100-$ 2000 for MS/MS. Each fraction from SCX chromatography was analyzed in duplicate.

2.5. Western Blot Analysis. The 14 most abundant proteins were depleted from sera from 6 RCC patients and 6 healthy people using a high capacity $4.6 \times 100 \mathrm{~mm}$ multiple affinity removal column. Total protein concentration was determined with Bio-Rad Protein Assay Dye Reagent Concentrate (BioRad, USA). Protein samples $(10 \mu \mathrm{g})$ were separated on a $10 \%$ SDS-PAGE gel, transferred to PVDF membranes, and probed with rabbit polyclonal antibodies to HSC71 (R\&D, USA) overnight at $4^{\circ} \mathrm{C}$. As there are no reliable internal control proteins for Western blot analysis of the serum samples, a loading control sample was generated by pooling all of the samples from all groups in equal volumes $(20 \mu \mathrm{L})$ for each gel. The optical intensity of each protein staining was determined using Quantity One. The loading control sample in each gel was used as the standard for quantification.

2.6. ELISA Analysis. Human heat shock cognate $71 \mathrm{kDa}$ protein ELISA kit from Huamei Biological Inc. (Wuhan, China) was purchased and used according to the manufacturer's instruction. The serum levels of HSC71 were assayed in the 30 RCC patients, 10 healthy controls, and 20 other urologic diseases patients. All serum samples and the standards were run in duplicate.

2.7. Statistical Data and Graphics. We performed the entire statistical analysis with SPSS 19.0. Student's $t$-test was applied for comparisons of quantitative data. We performed operating characteristic curve (ROC) analysis to quantify serum HSC71 positivity and statistical uncertainty. Data are expressed as the mean \pm standard deviation $(\mathrm{M} \pm \mathrm{SD})$. For all analysis, a $P$ value $<0.05$ was considered to indicate statistical significance.

\section{Results}

3.1. Quantitative Proteomic Analysis of Serum Proteins by $i T R A Q$. To identify dysregulated serum proteins between ccRCC patients and control group, we compared 10 ccRCC patients' sera and 10 healthy people's sera by iTRAQ quantitative proteomic analysis. Among 375 identified proteins, 16 proteins were increased more than 1.5 -fold and 14 proteins were decreased less than 0.67 -fold in the serum of early-stage ccRCC patients compared to that of healthy controls (Table 2). Furthermore, serum HSC71 was highly elevated compared to control group (3.07-fold upregulated expression) and was evaluated further for its potential as a serum biomarker for ccRCC.

3.2. Validation of Serum HSC71 Upregulation by Western Blot. To confirm the dysregulated expression of HSC71 in ccRCC patients and healthy controls sera, we performed Western blot analysis in six sets of discovery cohort individually (Figure 1(a)). Quantitative analysis showed that HSC71 was significantly upregulated in sera of $\operatorname{ccRCC}(P=0.0037)$
(Figure 1(b)), in agreement with our iTRAQ quantitative proteomic findings.

3.3. Validation of Serum HSC71 as a Novel Biomarker for ccRCC by ELISA. ELISA, performed in 30 ccRCC patients, 10 healthy people, and 20 patients with other urologic diseases (Table 1), showed significantly higher serum HSC71 levels in ccRCC patients versus the control group (10 healthy people and 20 other urologic diseases patients) (Figure 2(a)). These observations were consistent with the results obtained by iTRAQ analysis and Western blot, and the HSC71 concentrations obtained by ELISA were used to assess the clinical performances of the serum HSC71. The diagnostic values of serum HSC71 were evaluated by ROC curve analysis. The area under the receiver-operating characteristic curve (AUC) for differentiating between ccRCC and control group was 0.86 (95\% confidence interval (CI), 0.76 0.96), achieving sensitivity of $87 \%(95 \%$ CI $69 \% \sim 96 \%)$ at a specificity of $80 \%$ (95\% CI 61 92\%) with a threshold of $15 \mathrm{ng} / \mathrm{mL}$ (Figure 2(b)).

\section{Discussion}

In this study, we initially used two pooled samples for proteomic studies to identify the biomarker candidates using iTRAQ and LC-MS/MS. HSC71 was strongly increased in the sera samples from the RCC patients compared to control group. Then, we examined serum HSC71 levels of six sets of screening samples by Western blotting individually and confirmed that the data were comparable with quantitative proteomic analysis. Finally, we examined the clinical significance of HSC71 by ELISA in 30 RCC patients, 20 other urologic disease patients, and 10 healthy people to evaluate the clinical utilities of the candidate with ROC curve analysis. We demonstrated for the first time that serum HSC71 concentration is a biomarker for the diagnosis of RCC.

HSC71, also known as heat shock $70 \mathrm{kDa}$ protein 8 (HSPA8), is a member of the heat shock protein 70 family, located on chromosome 11q23.3. It is constitutively expressed under nonstressful conditions and also participated in protein folding as well as differentiation procedures $[8,9]$. Previous studies showed that upregulation of HSC71 in leukemic cells contributes to cell cycle disruption, and HSC71 binding to cyclin D1 in nuclei leads to the stabilization of the cyclin D1/CDK4 complex, promoting cell proliferation [10]. High levels of HSP70 family expression have been demonstrated in human cancers, which appear at least of prognostic value in osteosarcoma $[11,12]$. In the previous studies, heat shock proteins (HSPs) family expression is induced in a variety of kidney diseases suggesting that specific HSPs may have distinct functions in renal malignancies [13]. However, to our knowledge, no studies have evaluated the value of serum HSC71 in the potential diagnosis role for RCC.

Here we report raised HSC71 concentrations in sera from RCC patients compared with healthy people and other urologic diseases. HSPs have gained interest as a promising anticancer drug target, due to its importance in maintaining the stability, integrity, conformation, and function of key oncogenic proteins, including HSP40, HSP70, and HSP90 
TABLE 2: List of differentially expressed proteins in ccRCC compared to control group.

\begin{tabular}{|c|c|c|c|c|}
\hline Accession & Description & Score & Coverage & Ratio \\
\hline \multicolumn{5}{|c|}{ Proteins upregulated in ccRCC compared with control group } \\
\hline P11142 & Heat shock cognate $71 \mathrm{kDa}$ protein & 31.11 & $4.80 \%$ & 3.07 \\
\hline P02763 & Alpha-1-acid glycoprotein 1 & 251.48 & $40.80 \%$ & 2.087 \\
\hline Q16777 & Histone $\mathrm{H} 2 \mathrm{~A}$ type $2-\mathrm{C}$ & 164.19 & $49.61 \%$ & 1.984 \\
\hline P68871 & Hemoglobin subunit beta & 320.13 & $60.54 \%$ & 1.942 \\
\hline Q00532 & Cyclin-dependent kinase-like 1 & 20.04 & $1.96 \%$ & 1.828 \\
\hline P02748 & Complement C9 & 984.63 & $41.86 \%$ & 1.815 \\
\hline P02787 & Serotransferrin & 1689.45 & $61.46 \%$ & 1.775 \\
\hline P07360 & Complement component C8 gamma chain & 466.53 & $61.39 \%$ & 1.753 \\
\hline P02768 & Serum albumin & 2997 & $82.76 \%$ & 1.705 \\
\hline P69905 & Hemoglobin subunit alpha & 140.62 & $26.76 \%$ & 1.697 \\
\hline P25311 & Zinc-alpha-2-glycoprotein & 275.61 & $35.91 \%$ & 1.673 \\
\hline P01031 & Complement C5 & 2686.11 & $49.16 \%$ & 1.646 \\
\hline P68363 & Tubulin alpha-1B chain & 127.08 & $6.21 \%$ & 1.605 \\
\hline P00738 & Haptoglobin 1 alpha & 922.06 & $59.61 \%$ & 1.58 \\
\hline Q12931 & Heat shock protein $75 \mathrm{kDa}$ & 43.68 & $1.99 \%$ & 1.546 \\
\hline Q8NG11 & Tetraspanin-14 & 34.11 & $2.96 \%$ & 1.518 \\
\hline \multicolumn{5}{|c|}{ Proteins downregulated in ccRCC compared with control group } \\
\hline Q96KN2 & Beta-Ala-His dipeptidase & 142.84 & $12.62 \%$ & 0.651 \\
\hline Q5T686 & Arginine vasopressin-induced protein 1 & 45.27 & $4.08 \%$ & 0.643 \\
\hline P01614 & Ig kappa chain V-II region Cum & 83.17 & $33.04 \%$ & 0.627 \\
\hline P55056 & Apolipoprotein C-IV & 189.85 & $40.94 \%$ & 0.622 \\
\hline Q16610 & Extracellular matrix protein 1 & 643.87 & $34.44 \%$ & 0.614 \\
\hline Q96KK5 & Histone $\mathrm{H} 2 \mathrm{~A}$ type $1-\mathrm{H}$ & 177.42 & $50.00 \%$ & 0.606 \\
\hline P14618 & Pyruvate kinase PKM & 47.37 & $3.95 \%$ & 0.582 \\
\hline P33908 & Mannosyl-oligosaccharide & 60.74 & $4.75 \%$ & 0.495 \\
\hline P01019 & Angiotensinogen & 620.93 & $28.45 \%$ & 0.426 \\
\hline O60814 & Histone $\mathrm{H} 2 \mathrm{~B}$ type $1-\mathrm{K}$ & 67.21 & $15.87 \%$ & 0.419 \\
\hline Q15166 & Serum paraoxonase/lactonase 3 & 138.75 & $11.86 \%$ & 0.415 \\
\hline P68431 & Histone H3.1 & 24.05 & $5.15 \%$ & 0.377 \\
\hline P01815 & Ig heavy chain V-II region COR & 12.87 & $5.83 \%$ & 0.37 \\
\hline P62805 & Histone $\mathrm{H} 4$ & 171.24 & $45.63 \%$ & 0.353 \\
\hline
\end{tabular}

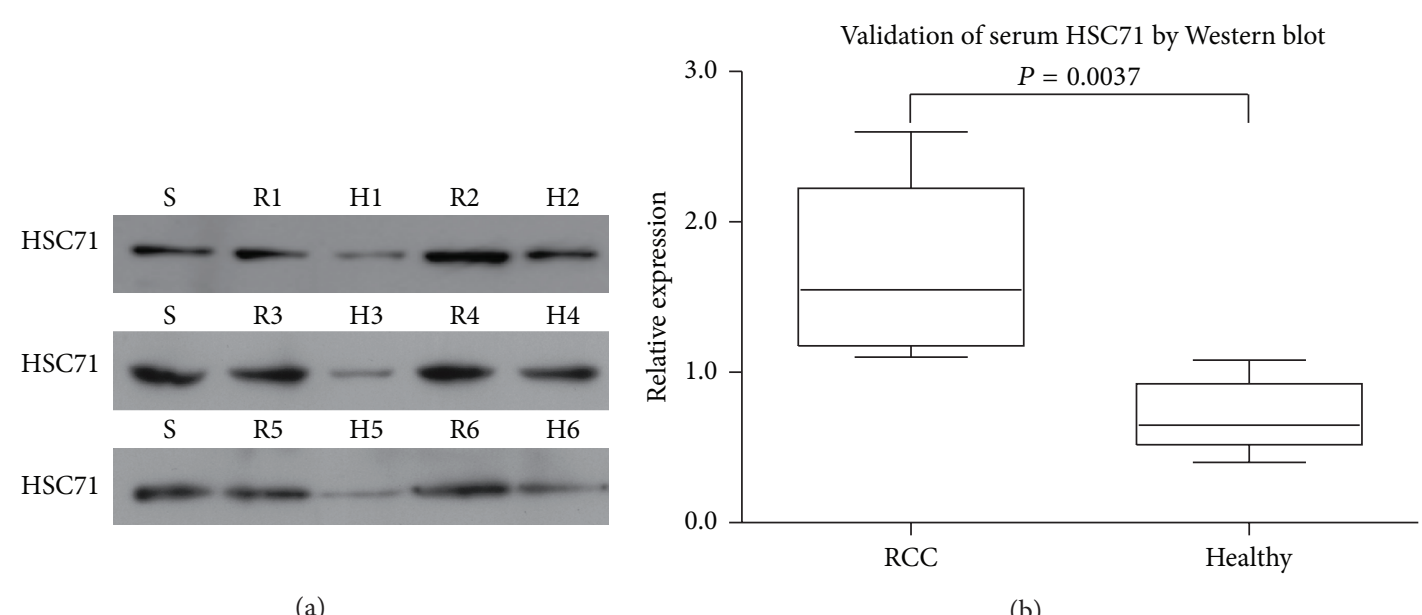

(a)

(b)

FIGURE 1: Validation of the serum HSC71 by Western blotting. (a) Serum HSC71 level was further examined using Western blotting in 6 additional serum samples from ccRCC patients (R1-R6) and healthy people (H1-H6). (b) Quantification of the densitometric analysis of the Western blotting bands was performed. The average concentration of HSC71 was 2.39-fold $(P=0.0037)$ higher in the RCC groups than in the Healthy group. 


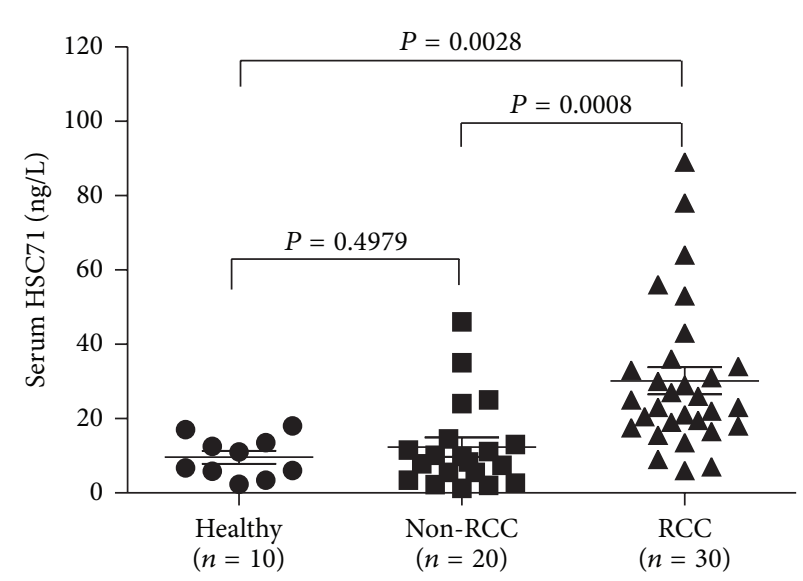

(a)

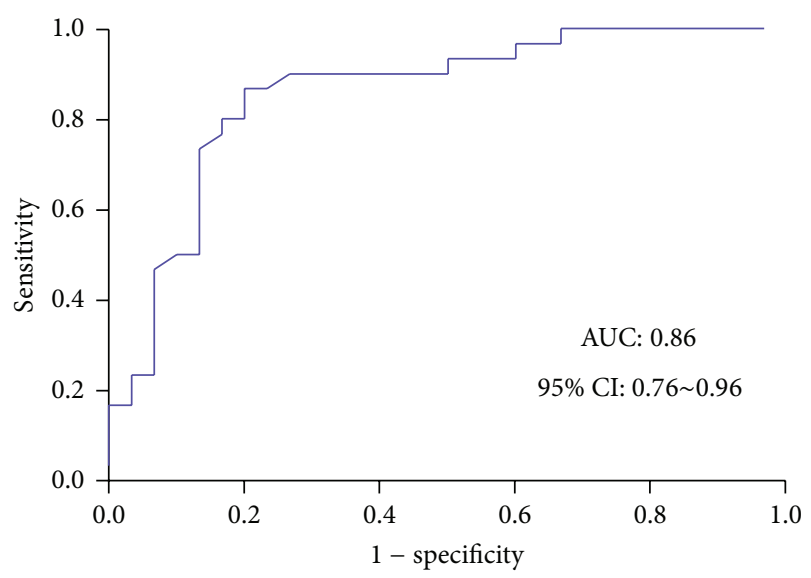

(b)

FIGURE 2: Validation of the diagnostic value of serum HSC71 concentration in RCC by ELISA. (a) The serum HSC71 concentration in 30 RCC patients, 10 healthy people, and 20 other urologic diseases (Non-RCC) was determined using ELISA. The mean concentrations of serum HSC71 in Healthy, Non-RCC, and RCC groups were 9.64, 12.34, and $30.17 \mathrm{ng} / \mathrm{L}$, respectively. Both Healthy and Non-RCC groups showed significantly lower levels of HSC71 than the RCC group $(P=0.0028, P=0.0008)$. (b) The receiver-operating characteristic curve (ROC curve) for the serum levels of HSC71 in patients with RCC compared with control group. The area under each curve is 0.86 (95\% CI, 0.76 0.96).

family members $[14,15]$. In addition, regarding the differentially expressed proteins, some of these were previously reported to be involved in RCC such as serum albumin [16], haptoglobin [17], and alpha-1-acid glycoprotein 1 [18], which provides confidence to our dataset and provides an independent confirmation of these candidates. In addition, previous studies have reported that prostate cancer, colon cancer, and squamous cell lung cancer may secrete common plasma proteins such as zinc-alpha-2-glycoprotein $[19,20]$ and complement C9 [21]. However, those candidate biomarkers need further research to confirm the clinical utility of as biomarker for diagnosis of RCC.

Clinical applications of serum HSC71 may require additional investigation. First, our results were obtained only for pT1-pT3 RCC patients; therefore, more pT4 and metastasis RCC patients should be included in the further validation studies. In addition, we could not show statistically significant correlation between serum HSC71 levels and different stages of RCC patients because of small patient numbers. The potential association of serum HSC71 with progression of RCC or tumor load requires further investigation using a larger sample. Second, the optimal cutoff value should be determined in a larger number of serum samples. Any single marker may not be sufficient for the final decision about therapeutic strategy, and all clinical and pathological information should be considered when using biomarker data. We do not consider that HSC71 is the only and best biomarker protein for RCC and the additional biomarker candidates should be further investigated using the other proteomic modalities.

\section{Conclusion}

In conclusion, using iTRAQ-based comparative proteomic analysis and validating by Western blotting and ELISA analysis, we identified serum HSC71 concentration as a novel biomarker for the diagnosis of RCC. Further investigation of the origin of serum HSC71 and the mechanisms underlying the correlation between serum HSC71 and carcinogenesis will allow greater insights into RCC biology.

\section{Conflict of Interests}

The authors declare that there is no conflict of interests regarding the publication of this paper.

\section{Authors' Contribution}

Yushi Zhang and Yi Cai contributed equally to this work.

\section{Acknowledgments}

This study was supported by the National Natural Science Foundation of China (Grant 30772165) and the Wu Jieping Medical Foundation (Grant 320.6750.13257).

\section{References}

[1] R. Siegel, J. Ma, Z. Zou, and A. Jemal, "Cancer statistics, 2014," CA: Cancer Journal for Clinicians, vol. 64, no. 1, pp. 9-29, 2014.

[2] A. Lopez-Beltran, J. C. Carrasco, L. Cheng, M. Scarpelli, Z. Kirkali, and R. Montironi, "2009 update on the classification of renal epithelial tumors in adults," International Journal of Urology, vol. 16, no. 5, pp. 432-443, 2009.

[3] M. S. Feldstein, D. J. Rhodes, A. S. Parker, R. R. Orford, and E. P. Castle, "The haphazard approach to the early detection of asymptomatic renal cancer: results from a contemporary executive health programme," BJU International, vol. 104, no. 1, pp. 53-56, 2009.

[4] L. A. Echan, H.-Y. Tang, N. Ali-Khan, K. Lee, and D. W. Speicher, "Depletion of multiple high-abundance proteins improves protein profiling capacities of human serum and plasma," Proteomics, vol. 5, no. 13, pp. 3292-3303, 2005. 
[5] S. Tonack, M. Aspinall-O’Dea, R. E. Jenkins et al., "A technically detailed and pragmatic protocol for quantitative serum proteomics using iTRAQ," Journal of Proteomics, vol. 73, no. 2, pp. 352-356, 2009.

[6] D. Xu, Y. Li, X. Li et al., "Serum protein S100A9, SOD3, and MMP9 as new diagnostic biomarkers for pulmonary tuberculosis by iTRAQ-coupled two-dimensional LC-MS/MS," Proteomics, vol. 15, no. 1, pp. 58-67, 2015.

[7] L.-R. Yan, D.-X. Wang, H. Liu et al., "A pro-atherogenic HDL profile in coronary heart disease patients: an iTRAQ labellingbased proteomic approach," PLoS ONE, vol. 9, no. 5, Article ID e98368, 2014.

[8] B. Bukau, E. Deuerling, C. Pfund, and E. A. Craig, "Getting newly synthesized proteins into shape," Cell, vol. 101, no. 2, pp. 119-122, 2000.

[9] Y. Matsuda, T. Ishiwata, H. Yoshimura, M. Hagio, and T. Arai, "Inhibition of nestin suppresses stem cell phenotype of glioblastomas through the alteration of post-translational modification of heat shock protein HSPA8/HSC71," Cancer Letters, vol. 357, no. 2, pp. 602-611, 2015.

[10] E. S. José-Enériz, J. Román-Gómez, L. Cordeu et al., "BCRABL1-induced expression of HSPA8 promotes cell survival in chronic myeloid leukaemia," British Journal of Haematology, vol. 142, no. 4, pp. 571-582, 2008.

[11] C. Sarto, P.-A. Binz, and P. Mocarelli, "Heat shock proteins in human cancer," Electrophoresis, vol. 21, no. 6, pp. 1218-1226, 2000.

[12] K. Trieb and R. Kotz, "Proteins expressed in osteosarcoma and serum levels as prognostic factors," International Journal of Biochemistry and Cell Biology, vol. 33, no. 1, pp. 11-17, 2001.

[13] F.-X. Beck, W. Neuhofer, and E. Müller, "Molecular chaperones in the kidney: distribution, putative roles, and regulation," American Journal of Physiology: Renal Physiology, vol. 279, no. 2, pp. F203-F215, 2000.

[14] R. E. Wang, "Targeting heat shock proteins 70/90 and proteasome for cancer therapy," Current Medicinal Chemistry, vol. 18, no. 27, pp. 4250-4264, 2011.

[15] W. Wen, W. Liu, Y. Shao, and L. Chen, "VER-155008, a small molecule inhibitor of HSP70 with potent anti-cancer activity on lung cancer cell lines," Experimental Biology and Medicine, vol. 239, no. 5, pp. 638-645, 2014.

[16] M. Stenman, A. Laurell, and M. Lindskog, "Prognostic significance of serum albumin in patients with metastatic renal cell carcinoma," Medical Oncology, vol. 31, no. 3, article 841, 2014.

[17] J. Tolson, R. Bogumil, E. Brunst et al., "Serum protein profiling by SELDI mass spectrometry: detection of multiple variants of serum amyloid alpha in renal cancer patients," Laboratory Investigation, vol. 84, no. 7, pp. 845-856, 2004.

[18] B. Ljungberg, K. Grankvist, and T. Rasmuson, "Serum acute phase reactants and prognosis in renal cell carcinoma," Cancer, vol. 76, no. 8, pp. 1435-1439, 1995.

[19] I. Katafigiotis, S. I. Tyritzis, K. G. Stravodimos et al., "Zinc $\alpha 2-$ glycoprotein as a potential novel urine biomarker for the early diagnosis of prostate cancer," BJU International, vol. 110, no. 11, pp. E688-E693, 2012.

[20] Y. Xue, F. Yu, D. Yan et al., "Zinc-alpha-2-glycoprotein: a candidate biomarker for colon cancer diagnosis in Chinese population," International Journal of Molecular Sciences, vol. 16, no. 1, pp. 691-703, 2015.

[21] A. Narayanasamy, J.-M. Ahn, H.-J. Sung et al., "Fucosylated glycoproteomic approach to identify a complement component
9 associated with squamous cell lung cancer (SQLC)," Journal of Proteomics, vol. 74, no. 12, pp. 2948-2958, 2011. 


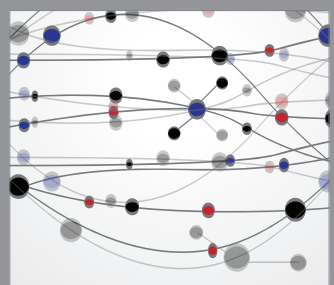

The Scientific World Journal
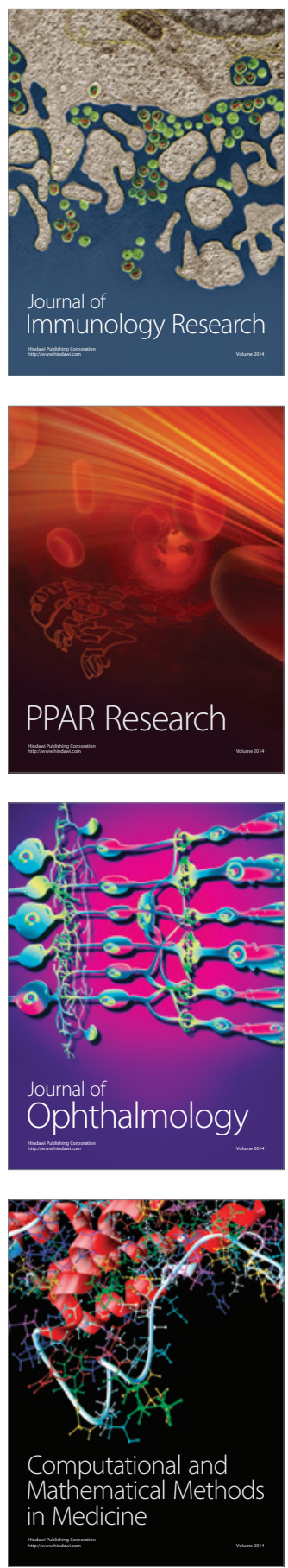

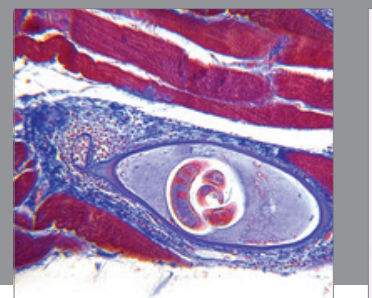

Gastroenterology

Research and Practice
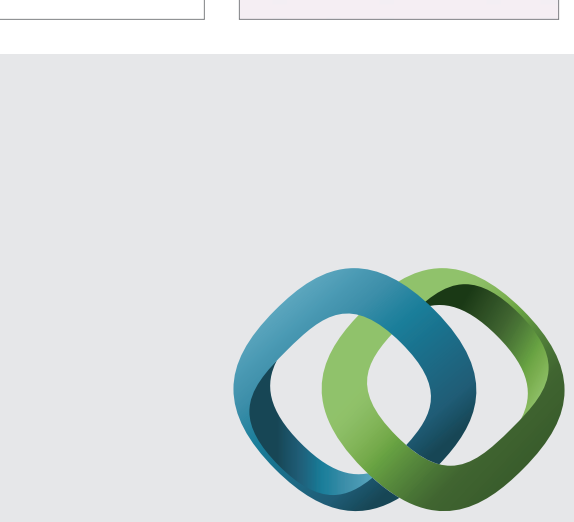

\section{Hindawi}

Submit your manuscripts at

http://www.hindawi.com
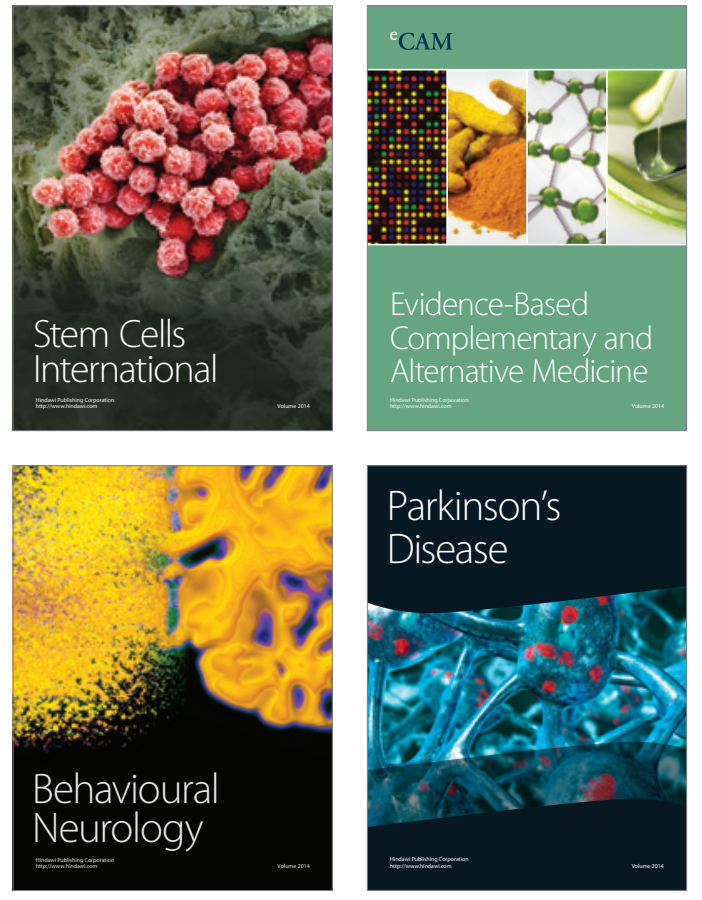
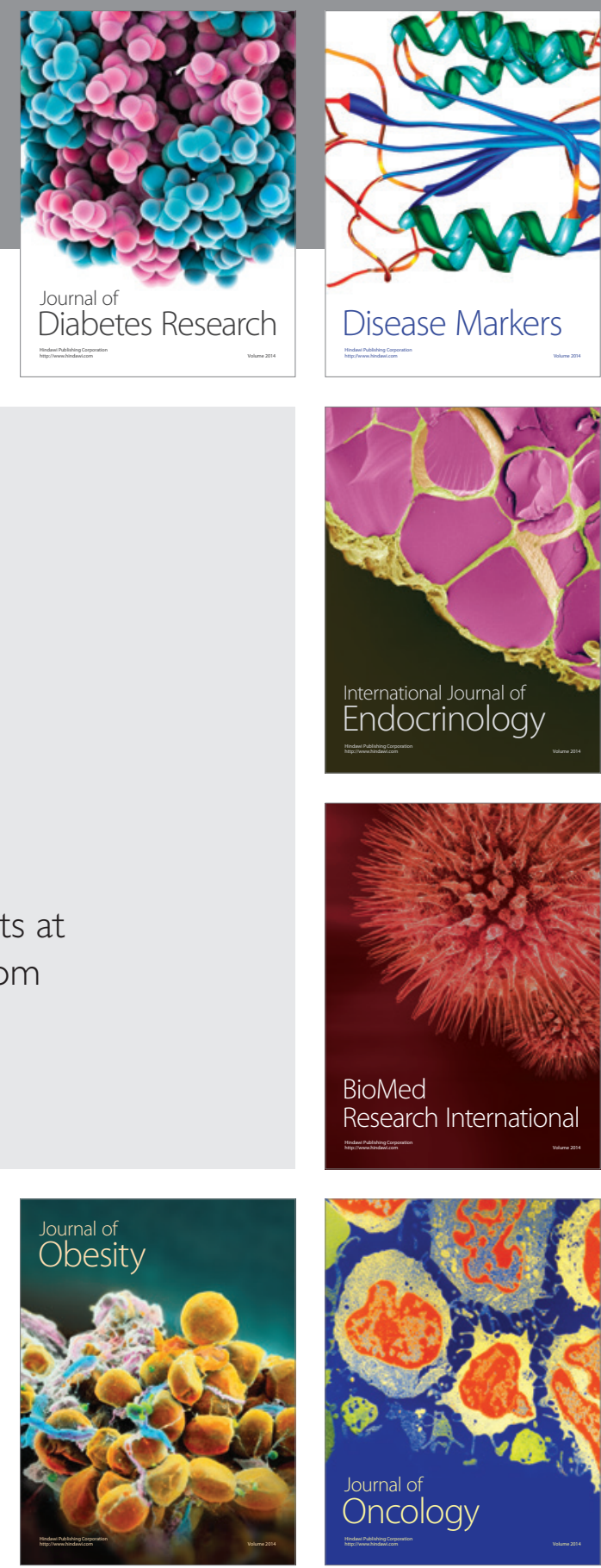

Disease Markers
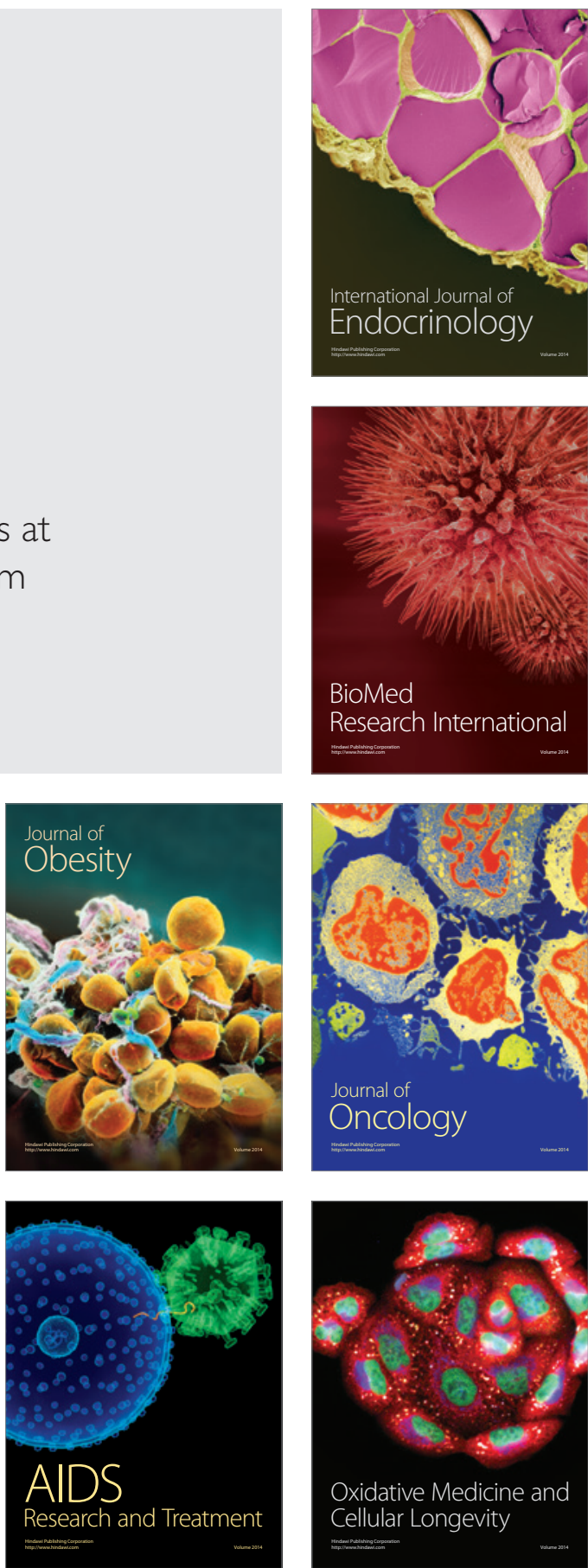